\title{
Tipos de escola primária e seus diferentes alcances sociais: algumas fontes de 1938 a 1946
}

\author{
Primary school types and their different social scope: \\ some sources from 1938 to 1946
}

\author{
Rosana Carla de Oliveira \\ Mestre em Educação \\ Universidade Federal de São Paulo-UNIFESP \\ São Paulo, SP, Brasil \\ rosanatts1@gmail.com \\ Mirian Jorge Warde \\ Doutora em Educação \\ Universidade Federal de São Paulo-UNIFESP \\ São Paulo, SP, Brasil \\ mjwarde@uol.com.br
}

Resumo: Este artigo centra atenção nos tipos de escolas primárias existentes no Brasil segundo levantamento de 1939, efetuado pelo O Instituto Nacional de Estudos Pedagógicos (INEP) e encaminhado para a Comissão Nacional do Ensino Primário, instalada em 1938 e responsável pela elaboração da primeira versão do anteprojeto que resultou na lei orgânica do ensino primário de 1946. O objetivo do artigo é basicamente alimentar os estudos em torno do assunto, mobilizando fontes pouco estudadas do período entre 1938 e 1946. A problemática que está na base deste artigo é a contradição contida em um grau de ensino, o primário, sobre o qual eram depositadas expectativas de unidade nacional e compartilhamento cultural e que, no entanto, é fragmentado, hierarquizado em modalidades que espelham discriminações e as desigualdades sociais certamente indesejáveis.

Palavras-chave: Tipos escolares. Modalidades escolares. Escola primária; Comissão nacional do ensino primário. INEP.

\begin{abstract}
This article focuses on the types of primary schools existing in Brazil according to a 1939 survey, carried out by National Institute for Pedagogical Studies (INEP) and sent to the National Commission for Primary Education, installed in 1938 and responsible for the preparation of the first draft of the preliminary project that resulted in the organic law of primary education, 1946. The objective of the article is basically to increase studies on the subject, mobilizing little studied sources from the period between 1938 and 1946. The problem that underlies this article is the contradiction contained in a level of education, the primary, on which expectations of national unity and cultural sharing were deposited and which, however, are fragmented, hierarchized in modalities that mirror discrimination and undesirable social inequalities.
\end{abstract}

Keywords: School types. School modalities. Primary school. Commission for primary education. INEP.

Cite como

\section{(ABNT NBR 6023:2018)}

OLIVEIRA, Rosana Carla; WARDE, Mirian Jorge. Tipos de escola primária e seus diferentes alcances sociais: algumas fontes de 1938 a 1946. Dialogia, São Paulo, n. 37, p. 1-19, e19774, jan./abr. 2021. Disponível em: https://doi.org/10.5585/dialogia.n37.19774.

American Psychological Association (APA)

Oliveira, R. C. de., \& Warde, M. J. (2021, jan./abr.). Tipos de escola primária e seus diferentes alcances sociais: algumas fontes de 1938 a 1946. Dialogia, São Paulo, 37, p. 1-19, e19774. https://doi.org/10.5585/dialogia.n37.19774. 
OLIVEIRA, Rosana Carla; WARDE, Mirian Jorge. Tipos de escola primária e seus diferentes alcances sociais:

\section{Introdução}

Getúlio Vargas, Presidente da República, e seu Ministro da Educação e Saúde, Gustavo Capanema, criaram, por meio do Decreto-Lei n. 868/1938, a Comissão Nacional de Ensino Primário (CNEP) “em caráter permanente” (BRASIL, 1939, art. 4). No mesmo dispositivo, fixaram a composição de sete membros a serem "escolhidos pelo Presidente da República, dentre pessoas notoriamente versadas em matéria de ensino primário e consagradas ao seu estudo, ao seu ensino ou à sua propagação" (BRASIL, 1939, art. $1^{\circ}$ ).

Decorridos dois meses, nos quais é cabível suspeitar de disputas, protestos contra invasão de competências e pedidos de esclarecimentos, Vargas e Capanema retornam com o Decreto-Lei n. 1.043/1939 para dispor sobre "as relações do Instituto Nacional de Estudos Pedagógicos com a Comissão Nacional de Ensino Primário”. No artigo $1^{\circ}$ do novo Decreto-Lei o diretor do Instituto Nacional de Estudos Pedagógicos (INEP) passa a fazer parte da CNEP, "em virtude de suas funções". A ele caberia dar à comissão "todos os elementos elucidativos necessários, bem como organizar o relatório de seus trabalhos" (art. $\left.2^{\circ}\right)^{1}$.

Em abril de 1939, o INEP cumpre a função que lhe cabe e envia alguns subsídios para a CNEP elaborados pela Secção de Documentação e Intercâmbio (SDI). Lourenço Filho estava na direção do INEP e Paschoal Lemme na chefia da SDI ${ }^{2}$. Ambos também compunham a referida Comissão Nacional, uma vez que Paschoal Lemme tinha sido nomeado como seu secretário. O documento encaminhado contém um quadro (o de número 1), em anexo, com o rol dos Tipos de Escola Primária e Expansão do Curso; era um "estudo preliminar".

Gustavo Capanema e, por decorrência, Getúlio Vargas incluíram o ensino primário na pauta de seus interesses políticos pressionados, de um lado, pela demanda que se avolumava nos centros urbanos; de outro, pela assessoria palaciana, cujo principal porta-voz era Lourenço Filho. Capanema era, originalmente, devotado ao ensino secundário e superior, enquanto Vargas investia no potencial adestrador das escolas profissionais; assim, a inclusão do ensino primário na pauta ministerial se deu com muito trabalho de convencimento. Afinal, havia mais de um século que o governo central tinha se livrado de financiar e coordenar a escola básica. O interesse pelo ensino primário se confirma pela grande quantidade de documentos em torno do assunto, depositados no arquivo de Capanema, guardado pelo Centro de Pesquisa e Documentação de História

\footnotetext{
${ }^{1}$ Composição da CNEP: "Everardo Backheuser, Major Euclides Sarmento, Gustavo Armbrust, Carlos Alberto Nobrega da Cunha, Alberto Ribeiro de Cerqueira Lima, Manoel Bergstrom Lourenço Filho, professora dona Maria dos Reis Campos e, como secretário dessa sessão, Paschoal Lemme, que, à época, era chefe da seção de Documentação e Intercâmbio do Instituto Nacional de Estudos Pedagógicos" (QUADROS; MACHADO, 2015, p. 415).

${ }^{2}$ Em 1941, Pachoal Lemme consta em relatório como chefe da Secção de Inquéritos e Pesquisas (MES/INEP, 1942).
} 
OLIVEIRA, Rosana Carla; WARDE, Mirian Jorge. Tipos de escola primária e seus diferentes alcances sociais:

Contemporânea do Brasil (CPDOC), muitos deles assinados por Lourenço Filho. Destaca-se a atenção especial que foi dedicada ao ensino rural, principalmente porque na cúpula do governo federal havia se disseminado a tese de que a difusão da escola na zona rural e a sua adequação ao meio, poderia ser arma eficaz para a redução do êxodo rural (PAIVA, 2003).

Este artigo tem como tema as modalidades de escolas de ensino primário existentes no país, tendo como ponto de partida o documento acima referido: Subsidios para a Comissão Nacional de Ensino Primário. Tipos de Escola Primária e Extensão do Curso (estudo preliminar), de 1939. A partir dele, são examinados dados e informações legais anteriores e posteriores que dizem respeito àquele tema em âmbito nacional.

O objetivo deste artigo é alimentar o interesse dos historiadores da educação por um tema já despertado, desde a segunda metade da década de 1990, pelos estudos de Souza (1998) e Faria Filho (2000), derivados de suas teses de doutorado, que trouxeram à baila os grupos escolares criados entre fins do sec. XIX e começo do sec. XX em São Paulo e Minas Gerais, respectivamente. A partir desses trabalhos, um largo número de outros títulos foram lançados sobre o mesmo tópico, seja reiterando os efeitos dos grupos escolares como signos da racionalidade moderna seja problematizando o alcance dessa modalidade de escola em relação às demais, sobretudo a isolada (SOUZA, 2019).

Esses estudos desenvolvidos em âmbito nacional, especialmente os de autoria de Souza (2019; 2016; 2009; 2008) ou sob sua coordenação (SOUZA; PINHEIRO; LOPES, 2015; SOUZA; SILVA; SÁ, 2013; ARAUJO; SOUZA; PINTO, 2012), permitem que se trabalhe com a hipótese de o grupo escolar ter se tornado hegemônico, ainda que não dominante, uma vez que se tornou parâmetro para estabelecimento e classificação dos demais tipos escolares - mais uma vez, com destaque à escola isolada - não impedindo, muito ao contrário, o surgimento de tipos escolares distintos, todos eles considerados inferiores em eficácia e eficiência ao grupo escolar; e, se não todos, a maioria destinada ao desaparecimento mediante o equacionamento dos inúmeros problemas da escola primária brasileira. Souza (2016) formulou de modo preciso a questão no caso de São Paulo:

\footnotetext{
Não obstante, apesar do reconhecimento público da ineficiência das escolas isoladas para a promoção da educação popular, a manutenção delas na estrutura do ensino público paulista foi decorrente de sua imprescindibilidade para a disseminação dos rudimentos da leitura, escrita e cálculo em zonas de povoamento disperso do estado.

Em síntese, a trajetória da escola isolada evidencia a necessidade de uma revisão da historiografia do ensino primário, dimensionando o lugar ocupado por essa instituição na escolarização da infância (SOUZA, 2016, p. 371-372).
} 
OLIVEIRA, Rosana Carla; WARDE, Mirian Jorge. Tipos de escola primária e seus diferentes alcances sociais:

E conclui

No que diz respeito ao estado de São Paulo, a despeito do número de alunos matriculados
nos grupos escolares ter sido muito maior do que nas escolas isoladas ao longo do século
XX, é preciso reconhecer o papel relevante que elas desempenharam, disseminando a
cultura escolar nos pequenos núcleos urbanos, nos bairros, vilas, distritos e, sobretudo,
nas zonas rurais do estado. A precariedade material e as diferenças pedagógicas das
escolas isoladas revelam o direcionamento dado pelos governos de São Paulo para a
democratização do ensino, desde o século XIX. A diferenciação entre tipos de escolas
primárias no século XX tornou-se um dispositivo de manutenção das desigualdades
sociais e educacionais (SOUZA, 2016, p. 372).

Embora importante, essa diferenciação tipológica da escola primária, que se avolumou a partir dos anos de 1920 marcando processos muito desiguais de escolarização, no entanto, como apontado pela mesma autora, já foi mapeada, porém não ainda devidamente esquadrinhadas pelos historiadores da educação (SOUZA, 2008; 2019).

Quanto aos problemas acumulados pela escola primária, não há como arrolá-los integralmente em curto espaço. O que se tem registrado desde o século XIX, informa que parte dos problemas foi reproduzida ad nauseam, sob diferentes formulações, em décadas sucessivas; uma parcela foi esquecida; uma outra, foi equacionada ou mitigada. No citado texto, Souza (2016) examina relatórios de professores paulistas da segunda metade do século XIX, nos quais aponta os problemas cotidianos por eles enfrentados: infrequência dos alunos; falta de instrumentos (adequados) de trabalho - livros, material para escrita, bancos, dentre outros; falta de preparo e baixa remuneração dos professores; instalações inadequadas, com pouco arejamento; ajuntamento num mesmo espaço e horário de crianças e jovens de diferentes idades e estágios de aprendizagem.

Esses e outros problemas serão apontados em anos sucessivos não só por professores, mas também por inspetores e ocupantes de postos mais altos da hierarquia dos governos locais e do nacional. Em 1940, Teixeira de Freitas, diretor do Serviço de Estatísticas da Educação e Saúde e Secretário Geral do Instituto Brasileiro de Geografia e Estatística (IBGE) e Lourenço Filho, diretor do INEP e Consultor Técnico do Conselho Nacional de Educação (CNE) escreveram diagnósticos pouco otimistas sobre o ensino primário. Para ambos, ao longo dos anos, foram observados progressos na oferta da escola primária, no entanto, destacam que o baixo crescimento no triênio de 1938 a 1940, comparados ao período anterior, justificava-se, basicamente, pelo relativo crescimento da população em idade escolar. Salientam que os levantamentos disponíveis indicam problemas relevantes da escola primária a serem enfrentados, e que só com a elaboração de uma lei orgânica poderia melhorar a situação desse grau de ensino.

Em suas análises, Lourenço Filho (1940) e Teixeira de Freitas (1940) apontavam os aspectos geográficos como um dos problemas do ensino primário e destacavam a magnitude da 
OLIVEIRA, Rosana Carla; WARDE, Mirian Jorge. Tipos de escola primária e seus diferentes alcances sociais:

expansão territorial do país que contava muitas regiões não escolarizáveis. Ainda, enfatizam que a distribuição demográfica era um dos maiores problemas encontrados. Havia a necessidade do conhecimento do conjunto da população escolar de todos os estados, o que era extremamente difícil para um país que se encontrava com sua rede escolar em franco desenvolvimento. Apontam também os aspectos da administração escolar nos diferentes estados, já que os sistemas de ensino eram tantos quantos as Unidades Federativas; com isso, as legislações de ensino diferiam no tocante a: idade para matrícula no primeiro ano, duração do ensino primário, faixa etária para escolarização obrigatória e tipos de escolas. Nos aspectos políticos destacam que, mesmo com a criação do Departamento Nacional de Educação ${ }^{3}$, pela Lei n. ${ }^{\circ}$ 378, de 13 de janeiro de 1937, incumbido da administração em nível federal das atividades relativas à educação escolar e à educação extraescolar, os problemas estavam longe de serem resolvidos devido "[...] [à] falta de uma legislação nacional, que levasse a União a coordenar os esforços dos Estados, os resultados de seus trabalhos têm sido pouco sensíveis" (LOURENÇO FILHO, 1940, pp. 656-657).

Teixeira de Freitas e Lourenço Filho, eram membros de um governo que interrompera o cumprimento da exigência constitucional de 1934 de elaborar um Plano Nacional de Educação, em função da decretação do Estado Novo, que passara a lidar sobre os graus e modalidades de ensino pelo velho método do fatiamento em distintos fóruns de decisão. O ensino primário foi destinado àquela comissão criada em 1938. Suas tarefas já eram, elas mesmas, evidência da inépcia dos dirigentes e do séquito de servidores para pensar a escola primária popular, igualitária e universal.

A primeira competência, ou seja, a primeira prioridade - "organizar o plano de uma campanha nacional de combate ao analfabetismo, mediante a cooperação de esforços do Governo Federal com os governos estaduais e municipais e ainda com o aproveitamento das iniciativas de ordem particular" (BRASIL, 1939, art. $2^{\circ}$ ) - é expressão cabal do equívoco com que se pensava o "combate ao analfabetismo" no Brasil por meio de campanhas. Ineficientes e caras, as campanhas fracassavam como todas as soluções pontuais para problemas estruturais. A segunda, diz respeito

\footnotetext{
${ }^{3}$ Que Lourenço Filho chefiara por três meses; há notícias de que teria deixado o cargo por divergências com o chefe de gabinete de Capanema, Carlos Drummond de Andrade.

${ }^{4} \mathrm{O}$ tom mais pessimista de Lourenço Filho e Teixeira de Freitas, dois dos maiores especialistas à época em estatísticas escolares, contrasta com o otimismo que Capanema manifesta anos depois com base nos mesmos dados. Passando por São Paulo, em setembro de 1943, Capanema em declara à imprensa que enormes progressos tinham sido realizados nos últimos 10 anos no ensino primário, mas a situação continuava grave e delicada. Em 09/02/1944 a redação de $O$ Jornal publica uma carta de um leitor que questionava as declarações otimistas dadas a imprensa pelo Ministro Gustavo Capanema. Declarações que apontavam o sentido contrário dos dados do INEP apresentados por Lourenço Filho e Teixeira de Freitas, sobretudo o Boletim n.25 que indicava o crescimento da educação primária no $1^{\circ}$ triênio de 1935 a 1937, maior que no $2^{\circ}$ triênio 1938 a 1940. Esse episódio levou a necessidade do envio de uma carta, ainda naquele mesmo mês de fevereiro de 1944, de Lourenço Filho ao Ministro explicando e justificando os dados e os movimentos estatísticos de 1932 a 1941 , bem como os meios de divulgação dos resultados. A carta destaca que dos 31 trabalhos impressos pelo INEP, 20 se referiam ao ensino primário, estudos que a imprensa e o público tinham se apropriado e por isso questionado.
} 
OLIVEIRA, Rosana Carla; WARDE, Mirian Jorge. Tipos de escola primária e seus diferentes alcances sociais:

à integração da esfera federal e das locais para "nacionalizar integralmente o ensino primário de todos os núcleos de população de origem estrangeira"; problema mal posto, expressão da miopia nacionalista do governo Vargas, executada de maneira violenta e sem oferta de boas alternativas quer para a população estrangeira aqui residente quer para a população periférica, dominantemente negra, para a qual a escola primária também era "coisa de estrangeiro".

À CNEP também competia pensar a obrigatoriedade e gratuidade do ensino primário! Ou seja, a uma comissão cabia refletir se obrigatoriedade e gratuidade deveriam viger no ensino primário, quando essas deveriam ser duas das pré-condições da escola básica e necessariamente, dois preceitos constitucionais. Assim como, na constituição devia estar fixada a laicidade plena da escola pública, assunto que também foi arrolado para ser pensado pela comissão ${ }^{5}$.

Ao término dos trabalhos, a CNEP não entregou, como era de se supor, uma escola primária equacionada; também não a pensou em termos populares, universais, democráticos, posto que não fora moldada para tal. Trabalhou principalmente pela nacionalização das escolas estrangeiras, até porque era uma das prioridades do governo. E deixou pronta uma minuta de lei que, remetida a mãos superiores, resultou no Decreto-Lei n.8.529, de 2 de janeiro de 1946, a Lei Orgânica do Ensino Primário.

Nesse novo reordenamento legal, o primeiro que o governo federal emitia para a escola primária desde a lei de 1827, aquela tipologia de escolas primárias existentes foi levada em conta? A lei de 1946 deu um passo importante para a unificação da escola primária?

\section{A tipologia da escola primária de 1939}

Do quadro de 1939, com o título Subsídios para a Comissão Nacional de Ensino Primário, enviado pelo INEP à CNE, constam informações sobre os tipos de estabelecimentos; a extensão da escolaridade em anos; a duração do ano letivo em meses; dados legais e observações adicionais,

\footnotetext{
5 “Art. $2^{\circ}$ Compete à Comissão Nacional de Ensino Primário:

a) organizar o plano de uma campanha nacional de combate ao analfabetismo, mediante a cooperação de esforços do Governo Federal com os governos estaduais e municipais e ainda com o aproveitamento das iniciativas de ordem particular;

b) definir a ação a ser exercida pelo Governo Federal e pelos governos estaduais e municipais para o fim de nacionalizar integralmente o ensino primário de todos os núcleos de população de origem estrangeira;

c) caraterizar a diferenciação que deve ser dada ao ensino primário das cidades e das zonas rurais;

d) estudar a estrutura a ser dada ao currículo primário bem como as diretrizes que devam presidir a elaboração dos programas do ensino primário;

e) opinar sobre as condições em que deve ser dado nas escolas primárias o ensino religioso;

f) indicar em que termos deve ser entendida a questão da obrigatoriedade do ensino primário;

g) estudar a questão da gratuidade do ensino primário, opinando sobre as contribuições com que as pessoas menos necessitadas

g) são obrigadas a concorrer para as caixas escolares, bem como sobre o destino a ser dado ao produto destas contribuições;

h) estudar a questão da preparação, da investidura, da remuneração e da disciplina do magistério primário de todo o país." (BRASIL, 1838).
} 
OLIVEIRA, Rosana Carla; WARDE, Mirian Jorge. Tipos de escola primária e seus diferentes alcances sociais: algumas fontes de 1938 a 1946

distribuídos pelo Distrito Federal, 20 estados e o Território do Acre. As referências legais dos tipos escolares arrolados variam em data desde a mais antiga de 1923, do Ceará, à então mais recente de 1938, da Paraíba. Delas, a Secção de Documentação e Intercâmbio do INEP extraiu a definição dessa variedade de escolas.

Algumas nomenclaturas se repetem, mas esse não pode ser tomado como sinal de homogeneidade. Sabe-se que sequer o grupo escolar, talvez o mais racionalizado dentre os tipos escolares primários existentes até então, multiplicou-se da mesma maneira por toda a parte, até porque sua difusão pelos estados se deu em ritmos e em conjunturas distintas. Nas demais, os anos letivos variavam de 8 a 10 meses e meio; e os cursos se estendiam de dois a seis anos. Excetue-se a "escola nuclear", no Piauí, para uma alfabetização rápida em povoados de população escassa, com apenas um ano de duração, com o ano letivo iniciando em 01 de março e terminando em 25 de novembro de cada ano. Essas diferenças são abissais, independentemente da nomenclatura que se adotava para a escola primária.

O Distrito Federal, pelo que consta do levantamento do INEP de 1939, distinguia-se em todos os sentidos dos vinte estados e do Acre (ver quadro anexo). Nele, aparece apenas uma modalidade de instituição primária, a "escola elementar" de cinco anos de duração e um funcionamento letivo de nove meses e meio. Embora desejável para todas as regiões, essa homogeneidade decorria de um lado da bem-sucedida reforma empreendida por Anísio Teixeira na primeira metade daquela década; de outro, o Distrito Federal correspondia apenas a um município, o Rio de Janeiro, com índice de urbanização relativamente elevado.

No extremo oposto ao Distrito Federal, quatro estados - Amazonas, Ceará, Pará e Paraíba - apresentavam cinco tipos de escolas; seguidos de seis estados com quatro tipos - Espírito Santo, Mato Grosso, Paraná, Piauí; seis estados e o Acre com três tipos - Alagoas, Bahia, Minas Gerais, Rio de Janeiro, São Paulo, Sergipe - com três e, por fim, Goiás, Maranhão, Pernambuco e Santa Catarina, com dois tipos, conforme se apresenta na tabela e quadro a seguir: 
OLIVEIRA, Rosana Carla; WARDE, Mirian Jorge. Tipos de escola primária e seus diferentes alcances sociais:

Tabela 1 -Tipos de escolas primárias mais frequentes ou denominações que se repetem, 1939

\begin{tabular}{|r|c|}
\hline \multicolumn{1}{|c|}{ Tipo } & Unidades federativas \\
\hline Grupo escolar & 21 \\
\hline \multicolumn{1}{|r|}{ rural } & 01 \\
\hline Escola Isolada & 06 \\
\hline rurbana & 09 \\
\hline diurna & 11 \\
\hline noturna & 01 \\
\hline distrital & 01 \\
\hline Escola Reunida & 01 \\
\hline Escola agrupada & $12 *$ \\
\hline Escola ambulante & 2 \\
\hline
\end{tabular}

Fonte: MES/INEP, 1939.

*Aqui está computada a modalidade "escola reunida ou agrupada" que aparece apenas no Paraná.

Quadro 1 - Nomenclaturas exclusivas das escolas primárias ou variações do mesmo, 1939

\begin{tabular}{|c|c|}
\hline Tipo & Unidades federativas \\
\hline Colégio & Rio Grande do Sul \\
\hline Escola Elementar & Distrito Federal \\
\hline Escola simples & Paraná \\
\hline Escola singular & Piauí \\
\hline
\end{tabular}

Fonte: MES/INEP, 1939.

Excetuado o Distrito Federal, em todos os 20 estados e no Território do Acre aparece o tipo "grupo escolar", com durações que variavam de quatro a seis anos e períodos letivos de oito meses e meio a dez meses e meio; diferenças, portanto, substantivas de funcionamento, de clientela, de professorado... Destaque-se que o estado de São Paulo é o único a apresentar a modalidade "grupo escolar rural" para ministrar "a educação primária" e procurar "desenvolver pendor e aptidão para atividades agrícolas e pastoris". O Rio Grande do Sul, por outro lado, é também o único que prevê oficialmente a modalidade "colégio" cuja organização coincide com a dos grupos escolares, “[...] mas são mais desenvolvidos, com maior matrícula etc” (MES/INEP, 1939).

Em 12 estados, há referência à "escola reunida", sendo que para o Paraná "reunida" e "agrupada" constituíam a mesma modalidade; para o Amazonas, eram duas modalidades diferentes e no Piauí só há referência à "agrupada". 
O tipo "escola isolada" se repete em 18 estados e no Acre, contendo os subtipos rural e urbana; para Minas Gerais, estava previsto também o subtipo "escola isolada distrital" e no Maranhão aparecem diferenciadas a "escola isolada diurna" e a "escola isolada noturna". Nos estados do Paraná e do Piauí onde essa modalidade não consta; em seu lugar, aparecem "escola simples" e "escola singular", respectivamente.

O tipo "escola ambulante" é um bom exemplo de como a mesma nomenclatura podia estar associada a definições distintas, ainda que próximas. A “escola ambulante” do Paraná está tipificada na legislação como aquela destinada aos "bairros onde o Governo não houvesse estabelecido escolas ou as não pudesse manter por ser insignificante a população escolar"; enquanto no Território do Acre "as escolas ambulantes são destinadas a alfabetização intensiva das crianças que vivem nos seringais e não podem permanecer por mais de um ano em cada seringal”. Referem-se ainda ao tipo "ambulante" a legislação do Mato Grosso que previa "escolas rurais ambulantes" a serem "criadas nas zonas de pequenos núcleos de população"; para o Rio Grande do Norte estavam previstas as "escolas rudimentares" que poderiam funcionar como "escolas ambulantes" por períodos ou ciclos de 5 meses.

A partir dessas modalidades, seguem-se outras tantas de inspiração mais local que se expressa em denominações peculiares; merecem atenção as insólitas modalidades projetadas com o propósito de profissionalização infantil precoce, que transpiram tendência da época de incremento do ensino profissional, por um lado; e, por outro, o intento de disseminação nas escolas das zonas rurais do gosto pelas atividades agrícolas e pastoris com a pretensão de controle do êxodo rural. São elas: 
OLIVEIRA, Rosana Carla; WARDE, Mirian Jorge. Tipos de escola primária e seus diferentes alcances sociais:

Quadro 2 - Tipos exclusivos ou variações nominais do mesmo

\begin{tabular}{|c|c|c|}
\hline Tipo & Localização & Observação \\
\hline Granja escolar & Alagoas & $\begin{array}{l}\text { As Escolas Isoladas da zona } \\
\text { rural eram transformadas em } \\
\text { Granjas Escolares, na medida } \\
\text { das possibilidades econômicas } \\
\text { do Estado. }\end{array}$ \\
\hline Escola de emergência & Amazonas & $\begin{array}{l}\text { As Escolas de Emergência } \\
\text { eram } \\
\text { anualmente, com o fim de } \\
\text { combater o analfabetismo. }\end{array}$ \\
\hline $\begin{array}{c}\text { Escola Profissional Rural } \\
\text { de } 1^{\circ} \text { grau }\end{array}$ & Ceará & $\begin{array}{l}\text { As Escolas Profissionais } \\
\text { Rurais de } 1^{\circ} \text { grau ministravam } \\
\text { educação elementar e iniciação } \\
\text { profissional agrícola e pastoril. }\end{array}$ \\
\hline $\begin{array}{c}\text { Escola primária profissional } \\
\text { de Juazeiro }\end{array}$ & Ceará & $\begin{array}{l}\text { A Escola Primária Profissional } \\
\text { de Juazeiro preparava para } \\
\text { profissões de base manual e } \\
\text { mecânica compreendendo as } \\
\text { fainas agrícolas e pastoril. }\end{array}$ \\
\hline Escola Desdobrada & Espírito Santo & $\begin{array}{l}\text { As Escolas que atingiam a } \\
\text { matrícula de } 65 \text { alunos ou a } \\
\text { frequência de } 45 \text { eram } \\
\text { desdobradas em período de } 3 \\
\text { horas. }\end{array}$ \\
\hline $\begin{array}{c}\text { Escola Auxiliar Suburbana } \\
\text { e Escola Afastada dos } \\
\text { Centros Urbanos }\end{array}$ & Pará & $\begin{array}{l}\text { Essas Escolas eram criadas em } \\
\text { lugares afastados e no interior } \\
\text { dos municípios. O ano letivo } \\
\text { compreendia } 9 \text { meses e } 9 \text { dias, } \\
\text { de } 15 \text { de janeiro a } 24 \text { de } \\
\text { outubro de cada ano. }\end{array}$ \\
\hline Escola Granja & Paraíba & $\begin{array}{l}\text { Escola Granja, além do ensino } \\
\text { de letras do programa oficial, } \\
\text { ministrava praticamente em } \\
\text { terreno doado pela Prefeitura } \\
\text { ou particular, ensino de } \\
\text { horticultura, jardinagem, } \\
\text { silvicultura, pomicultura, } \\
\text { suinocultura, cunicultura, } \\
\text { sericicultura e culinária. }\end{array}$ \\
\hline Escola Rural Modelo & Paraíba & $\begin{array}{l}\text { Escola Rural Modelo destina- } \\
\text { se a ministrar o ensino rural } \\
\text { especial aos alunos dos bairros } \\
\text { pobres da cidade, que tenham } \\
\text { sido aprovados nas matérias do } \\
3^{\circ} \text { ano do curso primário e } \\
\text { formar um professorado de } \\
\text { emergência. }\end{array}$ \\
\hline Escola nuclear & Piauí & $\begin{array}{l}\text { Escolas Nucleares para rápida } \\
\text { alfabetização em povoados de } \\
\text { população escassa. O ano } \\
\text { letivo começava em } 1.3 \text { e }\end{array}$ \\
\hline
\end{tabular}


OLIVEIRA, Rosana Carla; WARDE, Mirian Jorge. Tipos de escola primária e seus diferentes alcances sociais:

\begin{tabular}{|c|l|l|}
\hline & & $\begin{array}{l}\text { terminava em 25.11 de cada } \\
\text { ano. }\end{array}$ \\
\hline Escola típica rural & Rio de Janeiro & $\begin{array}{l}\text { Escola Típicas Rurais eram } \\
\text { escolas de educação elementar } \\
\text { e de iniciação profissional } \\
\text { agrícola. }\end{array}$ \\
\hline $\begin{array}{c}\text { Escola rudimentar (fixa e } \\
\text { ambulante) }\end{array}$ & Rio Grande do Norte & $\begin{array}{l}\text { As Escolas Rudimentares } \\
\text { podiam funcionar como } \\
\text { Escolas Ambulantes, por } \\
\text { períodos ou ciclos de 5 meses }\end{array}$ \\
\hline
\end{tabular}

Fonte: MES/INEP, 1939.

Conclusão.

O que foi feito da diversidade, ou melhor, da desigualdade entre as escolas primárias

Com certeza, boa parte dos tipos acima apresentados, com base nas legislações locais, não foi implantada. É quase certo que o descumprimento das prescrições legais não foi em favor da população em idade escolar; especialmente as populações pobres, das zonas rurais ou periféricas dos grandes centros, continuaram desassistidas de qualquer tipo de escola, mesmo as mais precárias, de mais baixo custo, justificadas em nome das peculiaridades locais, das singularidades culturais, mas reguladas com vistas ao alívio de estatísticas exasperantes.

Lourenço Filho, no comando do INEP de 1938 a 1946, produziu uma grande quantidade de documentos, postos à disposição de Capanema e da CNEP. Do relatório que encaminhou ao ministro sobre as atividades desenvolvidas pelo INEP em 1941, salienta os levantamentos efetuados de toda legislação de ensino em vigência no país, assim como minuciosos inventários sobre a situação do ensino primário, a formação dos professores primários, os problemas das escolas normais, os programas das escolas primárias e normais, além de estudos sobre outros graus e modalidades de ensino. Especial atenção é conferida à publicação dos Boletins do Instituto números 12 e 13, nos quais estão expostos estudos sobre os levantamentos efetuados em todo o país sobre a "situação geral do ensino primário" (MES/INEP, 1942). O levantamento completo foi publicado em 20 volumes independentes, correspondentes aos vintes Estados. Lourenço Filho apresentou suas análises sobre os dados coletados no Boletim nº 13, de 1941.

O então ministro da educação e saúde, Raul Leitão da Cunha, na sua Exposição de Motivos (1945), salienta todo o trabalho realizado pelo INEP, primeiro em apoio à CNEP, para redação de um anteprojeto de lei orgânica, publicado no Diário Oficial, de 20 de dezembro de 1939, e depois em assistência ao ministério para a coleta e sistematização de sugestões apresentadas nacionalmente a partir daí. O INEP cuidou da última redação do anteprojeto apresentado ao ministro, Leitão da 
OLIVEIRA, Rosana Carla; WARDE, Mirian Jorge. Tipos de escola primária e seus diferentes alcances sociais:

Cunha, visando já seu encaminhamento para votação, resultando no Decreto-Lei n. 8.529/1946, a Lei Orgânica do Ensino Primário. Portanto, aquele quadro com os tipos de escolas primárias, de 1939, foi um dos primeiros subsídios do Instituto, sob o comando de Lourenço Filho, para a elaboração da primeira lei republicana do ensino primário, aprovada sete anos depois.

A lei orgânica do ensino primário de 1946 aponta no sentido de uma certa concentração dos tipos escolares; mas não suficientemente, uma vez que reafirma algumas modalidades que deveriam já ter sido superadas e deixa em aberto adaptações locais que, na maioria dos estados tendia à simplificação, ao encurtamento e à desvalorização.

O ensino primário previsto para todo o país comportaria duas categorias: o ensino primário fundamental (sete a doze anos) a ser ministrado em dois cursos sucessivos: o elementar de quatro anos e o complementar de um ano; e o ensino primário supletivo (adolescentes e adultos) com duração apenas dois anos (art. $2^{\circ}, 3^{\circ}$ e $\left.4^{\circ}\right)$.

Os artigos 14 e 15, que tratam do ano escolar, preveem dez meses letivos e deixam em aberto a duração dos períodos letivos e os de férias a serem fixados "segundo as conveniências regionais, indicadas pelo clima, e, zonas rurais, atendidos, quanto possível, os períodos de fainas agrícolas".

Quanto aos tipos, a lei prevê quatro modalidades de instituições primárias, públicas ou privadas:

Escola isolada (E.I.), quando possua uma só turma de alunos, entregue a um só docente. Escolas reunidas (E.R.), quando houver de duas a quatro turmas de alunos, e número correspondente de professores.

Grupo escolar (G.E.), quando possua cinco ou mais turmas de alunos, e número igual ou superior de docentes.

Escola supletiva (E.S,), quando ministre ensino supletivo, qualquer que seja o número de turmas de alunos e de professores (BRASIL, 1946, art. 58).

Se as unidades da federação mantiveram a tendência anteriormente registrada de pulverização dos tipos escolares, outros estudos devem procurar responder a essa pergunta com a profundidade e minúcias devidas. Aqui, é dado apenas enfatizar que o trabalho realizado pela CNEP e em tempo mais largo pelo INEP foi suficiente para projetar uma escola primária mais homogênea, mas não suficientemente igualitária, uma que manteve uma profunda distinção entre o ensino para as regiões mais pobres, mais desguarnecidas de equipamentos sociais e mais distantes dos grandes centros. 
OLIVEIRA, Rosana Carla; WARDE, Mirian Jorge. Tipos de escola primária e seus diferentes alcances sociais: algumas fontes de 1938 a 1946

\section{Referências}

ARAUJO, José Carlos de S.; SOUZA, Rosa Fátima de; PINTO, Rubia-Mar N. (orgs.). Escola primária na Primeira República (1889-1930): subsídios para uma história comparada. Araraquara: Junqueira \& Marin, 2012.

BRASIL. Exposição de Motivos, de 28 de dezembro de 1945, que encaminha Decreto-Lei n. 8. 529, de 2 de janeiro de 1946. Disponível em: https://www2.camara.leg.br/legin/fed/declei/19401949/decreto-lei-8529-2-janeiro-1946-458442-133655-pe.html. Acesso em: 31 de março de 2021.

BRASIL. Decreto-Lei n. 8. 529, de 2 de janeiro de 1946. Lei Orgânica do Ensino Primário. Disponível em: https://www2.camara.leg.br/legin/fed/declei/1940-1949/decreto-lei-8529-2janeiro-1946-458442-publicacaooriginal-1-pe.html. Acesso em: 31 de março de 2021.

BRASIL. Decreto-Lei n ${ }^{\circ}$ 868, de 18 de novembro de 1938. Cria, no Ministério da Educação e Saúde, a Comissão Nacional de Ensino Primário. Disponível em: https:/ /www2.camara.leg.br/legin/fed/declei/1930-1939/decreto-lei-868-18-novembro-1938350829-publicacaooriginal-1-pe.html. Acesso em: 15 de março de 2021.

BRASIL. Decreto-Lei $n^{\circ}$ n. 1.043, 11 de janeiro de 1939. Dispõe sobre as relações do Instituto Nacional de Estudos Pedagógicos com a Comissão Nacional de Ensino Primário. Disponível em: https://www.lexml.gov.br/urn/urn:lex:br:federal:decreto.lei:1939-01-11;1043, Acesso em: 15 de março de 2021.

BRASIL. Decreto-lei n.8.529, de 2 de janeiro de 1946, Lei Orgânica do Ensino Primário. Disponível em: https:/ /www.lexml.gov.br/urn/urn:lex:br:federal:decreto.lei:1946-01-02;8529. Acesso em: 30 de março de 2021.

CAPANEMA, Gustavo. A situação do ensino primário - Declaração de Gustavo Capanema a imprensa em 1943. CPDOC. Arquivo Gustavo Capanema; GC g 1936.07.00, de 07/1936 a 30/09/1945. Disponível em:

https://docvirt.com/docreader.net/DocReader.aspx?bib=ARQ_GC_G\&pagfis=40991. Acesso em: 28 de março de 2021.

FARIA FILHO, Luciano Mendes. Dos pardieiros aos palácios: cultura escolar e urbana em Belo Horizonte na Primeira República. Passo Fundo: Universidade De Passo Fundo, 2000.

JORNAL (O), 09/02/1944. Carta à redação do jornal- Críticas à Política de Gustavo Capanema. CPDOC. Arquivo Gustavo Capanema; GC g 1936.07.00. Disponível em: https://docvirt.com/docreader.net/DocReader.aspx?bib=ARQ_GC_G\&pagfis=41003. Acesso em: 28 de março de 2021.

LOURENÇO FILHO, Manoel B. Alguns aspectos da educação primária. Revista Brasileira de Estatística, Rio de Janeiro, ano I, n. 4, p. 649-664, 1940.

LOURENÇO FILHO, Manoel B. Carta de Lourenço Filho a Gustavo Capanema justificando os dados apresentados pelo "O Jornal” 1944. CPDOC. Arquivo Gustavo Capanema; GC g 1936.07.00. Disponível em:

https://docvirt.com/docreader.net/DocReader.aspx?bib=ARQ_GC_G\&pagfis=40997. Acesso em: 28 de março de 2021. 
OLIVEIRA, Rosana Carla; WARDE, Mirian Jorge. Tipos de escola primária e seus diferentes alcances sociais:

MINISTÉRIO DA EDUCAÇÃO E SAÚDE. INSTITUTO NACIONAL DE ESTUDOS PEDAGÓGICOS. Subsídios para a Comissão Nacional de Ensino Primário. Tipos de Escola Primária e Extensão do Curso (Estudo Preliminar). Quadro I. Secção de Documentação e Intercâmbio, abril de 1939. CPDOC. Arquivo Gustavo Capanema; MES - Educação e Cultura $\backslash$ GC g 1936.07.00. Disponível em: https://docvirt.com/docreader.net/DocReader.aspx?bib=ARQ_GC_G\&pagfis=40912 Acesso em: em 15 de março de 2021.

MINISTÉRIO DA EDUCAÇÃO E SAÚDE. INSTITUTO NACIONAL DE ESTUDOS PEDAGÓGICOS. Atividade no ano de 1941. Relatório apresentado ao Sr. Ministro Dr. Gustavo Capanema, pelo Diretor do Instituto, prof. Lourenço Filho, janeiro de 1942. CPDOC. Arquivos Gustavo Capanema; MES- Educação e Cultura \GC g 1938.06.30 (2). Disponível em: https:/ / docvirt.com/docreader.net/DocReader.aspx?bib=ARQ_GC_G\&pagfis=5569. Acesso em: 28 de março de 2021.

PAIVA, Vanilda. História da educação popular no Brasil: educação popular e educação de adultos. São Paulo: Loyola, 2003.

QUADROS, Raquel dos S.; MACHADO, Maria Cristina G. Gustavo Capanema: criação da Comissão Nacional do Ensino Primário. Educação, v. 40, n. 2, p. 413-424, maio/ago. 2015.

SOUZA, Rosa Fátima. História da organização do trabalbo escolar e do currículo no século XX (ensino primário e secundário no Brasil). São Paulo: Cortez, 2008.

SOUZA, Rosa de Fátima Chaloba. A contribuição dos estudos sobre grupos escolares para a historiografia da educação brasileira: reflexões para debate. Revista Brasileira de História da Educação, v. 19, p. 01-24, 2019.

SOUZA, Rosa Fátima de. A configuração das Escolas Isoladas no estado de São Paulo (18461904). Revista Brasileira de História da Educação, v. 16, n. 2 [41], p. 341-337, 2016.

SOUZA, Rosa Fátima de. Alicerces da pátria: história da escola primária no estado de São Paulo (1890-1976). Campinas: Mercado de Letras, 2009.

SOUZA, Rosa Fátima de. Templos de civilização: a implantação da escola primária graduada no Estado de São Paulo (1890-1910). São Paulo: UNESP, 1998.

SOUZA, Rosa Fátima de; PINHEIRO, Antonio Carlos Ferreira; LOPES, Antônio de Pádua Carvalho (orgs). História da Escola Primária no Brasil: investigação em perspectiva comparada em âmbito nacional. Aracaju: Edise, 2015.

SOUZA, Rosa Fátima de; SILVA, Vera Lucia G. da; SÁ, Elizabeth F. de (Orgs.). Por uma teoria e uma história da escola primária no Brasil: investigações comparadas sobre a escola graduada (18701930). Cuiabá: EdUFMT, 2013.

TEIXEIRA DE FREITAS, Mário A. A evasão escolar no Ensino Primário Brasileiro. Revista Brasileira de Estatística, Rio de Janeiro, ano I, n. 4, p. 697-722, 1940. 


\section{Anexo}

Quadro 3 -Tipos de Escola Primária e Extensão do Curso (estudo preliminar) - 1939

\begin{tabular}{|c|c|c|c|c|c|}
\hline $\begin{array}{l}\text { Unidades } \\
\text { Federais }\end{array}$ & $\begin{array}{l}\text { Data e Origem da } \\
\text { Informação }\end{array}$ & $\begin{array}{c}\text { Tipos de } \\
\text { Estabelecimentos }\end{array}$ & $\begin{array}{l}\text { Extensão da } \\
\text { Escolaridade } \\
\quad \text { (anos) }\end{array}$ & $\begin{array}{c}\text { Ano letivo } \\
\text { (meses) }\end{array}$ & Observação \\
\hline $\begin{array}{l}\text { Distrito } \\
\text { Federal }\end{array}$ & $\begin{array}{l}\text { Dec. N. } 4.387 \text { de } 8 \text { de } \\
\text { setembro de } 1933 \text { e ato de } 27 \\
\text { de abril de } 1936 \text { do Secretário } \\
\text { Geral de Educação e Cultura, } \\
\text { mandando adotar } \\
\text { "Programas mínimos" }\end{array}$ & 1 - Escola Elementar & 5 & $9 \frac{1}{2}$ & EMBRANCO \\
\hline Alagoas & $\begin{array}{l}\text { Dec. N. } 2.225 \text { de } 30 \text { de } \\
\text { dezembro de } 1936 \\
\text { (Regulamento da Instrução } \\
\text { Pública) }\end{array}$ & $\begin{array}{l}1 \text { - Grupo Escolar } \\
2 \text { - Escola Isolada (urbana) } \\
\text { (rural) } \\
3 \text { - Granja Escolar }\end{array}$ & $\begin{array}{c}4 \\
3 \\
3 \\
---\end{array}$ & $101 / 2$ & $\begin{array}{l}\text { As Escolas Isoladas da zona rural serão } \\
\text { transformadas em Granjas Escolares, na medida } \\
\text { das possibilidades econômicas do Estado (art. } 42 \\
\text { do decreto citado) }\end{array}$ \\
\hline Amazonas &  & $\begin{array}{l}1 \text { - Grupo Escolar } \\
2 \text { - Escola Reunida } \\
4 \text { - Escola Agrupada } \\
4 \text { - Escola Isolada } \\
5 \text { - Escolas de Emergência }\end{array}$ & $\begin{array}{r}5 \\
5 \\
5 \\
3 \\
---\end{array}$ & 9 & $\begin{array}{l}\text { As Escolas de Emergência serão estabelecidas } \\
\text { anualmente, com o fim de combater o } \\
\text { analfabetismo (art. } 11 \text { do dec. Cit.). }\end{array}$ \\
\hline Bahia & $\begin{array}{l}\text { Dec. N. } 4.218 \text { de } 30 \text { de } \\
\text { dezembro } \\
\text { (Regulamento de }\end{array}$ & $\begin{array}{l}1 \text { - Grupo Escolar } \\
2 \text { - Escola Reunida } \\
3 \text { - Escola Isolada (urbana) } \\
\text { (rural) } \\
\end{array}$ & $\begin{array}{l}4 \\
4 \\
4 \\
3\end{array}$ & $101 / 2$ & EMBRANCO \\
\hline Ceará & $\begin{array}{l}\text { Dec. n. } 474 \text { de } 2 \text { de janeiro de } \\
1923 \text { (Regulamento da } \\
\text { Instrução Publica). } \\
\text { Lei n. } 272 \text { de } 30 \text { de dezembro } \\
\text { de } 1936 . \\
\text { Lei n. } 111 \text { de } 20 \text { de maio de } \\
\text { 1936. }\end{array}$ & $\begin{array}{l}\text { 1- Grupo Escolar } \\
2 \text { - Escolas Reunida } \\
3 \text { - Escola Isolada (urbana) } \\
4 \text { (rural) } \\
4-\text { Escola Profissional } \\
\text { Rural de } 1^{\circ} \text { grau } \\
5 \quad-\text { Escola Primária } \\
\text { Profissional de Juazeiro. }\end{array}$ & $\begin{array}{l}4 \\
3 \\
3 \\
3 \\
4 \\
3\end{array}$ & 10 & $\begin{array}{l}\text { As Escolas Profissionais Rurais de } 1^{\circ} \text { grau } \\
\text { ministram educação elementar e iniciação } \\
\text { profissional agrícola e pastoril (arts. } 4^{\circ} \text { e } 5^{\circ} \text { da lei } \\
\text { cit. } \\
\text { A Escola Primária Profissional de Juazeiro } \\
\text { prepara para profissões de base manual e } \\
\text { mecânica compreendendo as fainas agrícolas e } \\
\text { pastoril (art. } 1^{\circ} \text { da lei citada) }\end{array}$ \\
\hline
\end{tabular}




\begin{tabular}{|c|c|c|c|c|c|}
\hline $\begin{array}{l}\text { Espírito } \\
\text { Santo }\end{array}$ & $\begin{array}{l}\text { Comunicado da Diretoria } \\
\text { Geral de Informações, } \\
\text { Estatística e Divulgação do } \\
\text { Ministério da Educação } \\
\text { (25.5.933). Dec. } 6.501 \text { de } 20 \\
\text { de dezembro de } 1924\end{array}$ & $\begin{array}{l}1 \text { - Grupo Escolar } \\
2 \text { - Escolas Reunida } \\
3 \text { - Escola Isolada (urbana) } \\
\text { (rural) } \\
4 \text { - Escolas Desdobrada }\end{array}$ & $\begin{array}{c}4 \\
4 \\
4 \\
3 \\
---\end{array}$ & 10 & $\begin{array}{l}\text { As Escolas que atingirem a matrícula de } 65 \text { alunos } \\
\text { ou a frequência de } 45 \text { serão desdobradas em } \\
\text { período de } 3 \text { horas (Com. cit). }\end{array}$ \\
\hline Goiás & $\begin{array}{l}\text { Comunicado da Diretoria } \\
\text { Geral de Informações, } \\
\text { Estatística e Divulgação do } \\
\text { Ministério da Educação } \\
(9.5 .933) \text {. }\end{array}$ & $\begin{array}{l}1 \text { - Grupo Escolar } \\
2 \text { - Escola Isolada (urbana) } \\
\text { (rural) }\end{array}$ & $\begin{array}{l}3 \\
3 \\
2\end{array}$ & 10 & EMBRANCO \\
\hline Maranhão & $\begin{array}{l}\text { Comunicado da Diretoria } \\
\text { Geral de Informações, } \\
\text { Estatística e Divulgação do } \\
\text { Ministério da Educação } \\
\text { (6.5.933). Dec. n. } 852 \text { de 2- } \\
\text { março de 19321. }\end{array}$ & $\begin{array}{l}1 \text { - Grupo Escolar } \\
2 \text { - Escola Isolada (diurna) } \\
\text { (noturna) }\end{array}$ & $\begin{array}{l}5 \\
4 \\
3\end{array}$ & EM BRANCO & EMBRANCO \\
\hline Mato Grosso & $\begin{array}{l}\text { Dec. n. } 759 \text { de } 22 \text { de abril de } \\
1927 \quad-\text { Regulamento da } \\
\text { Instrução Pública }\end{array}$ & $\begin{array}{l}\text { 1- Grupo Escolar } \\
2 \text { - Escolas Reunida } \\
3 \text { - Escola Isolada (urbana) } \\
4 \quad \text { (rural) } \\
\text { Ambulante }\end{array}$ & $\begin{array}{l}4 \\
3 \\
3 \\
2 \\
-\end{array}$ & 9 & $\begin{array}{l}\text { As Escolas Rurais Ambulantes serão criadas nas } \\
\text { zonas de pequenos núcleos de população (art. } \\
253 \text { do dec. cit). }\end{array}$ \\
\hline Minas Gerais & 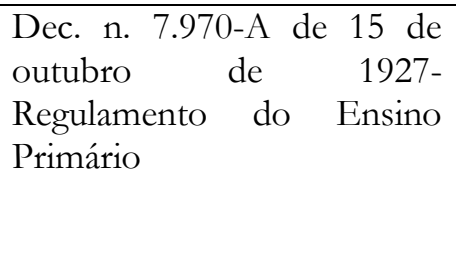 & $\begin{array}{l}\text { 1- Grupo Escolar } \\
\text { 2- Escolas Reunida } \\
\text { 3- Escola Isolada (urbana) } \\
\text { (distrital) (rural) }\end{array}$ & $\begin{array}{l}4 \\
4 \\
3 \\
3 \\
3\end{array}$ & 10 & EMBRANCO \\
\hline $\begin{array}{l}\text { Pará } \\
\end{array}$ & $\begin{array}{l}\text { Dec. n. } 1.650 \text { de } 1 \text { de abril de } \\
\text { 1935- Regulamento do } \\
\text { Ensino Primário }\end{array}$ & $\begin{array}{l}\text { 1- Grupo Escolar } \\
\text { 2- Escolas Reunida } \\
\text { 3- Escola Isolada }\end{array}$ & $\begin{array}{l}5 \\
3 \\
3 \\
3\end{array}$ & 9 & $\begin{array}{l}\text { As Escolas Auxiliares ou de Alfabetização são as } \\
\text { criadas no interior dos municípios. (art. } 71 \text { do dec. } \\
\text { cit.) O ano letivo compreende } 9 \text { meses e } 9 \text { dias, }\end{array}$ \\
\hline
\end{tabular}




\section{Dialogia}

\begin{tabular}{|c|c|c|c|c|c|}
\hline & & $\begin{array}{l}\text { 4- Escola Auxiliar } \\
\text { Suburbana } \\
5-\text { Escola Afastada dos } \\
\text { Centros Urbanos (Isoladas } \\
\text { e Auxiliares) }\end{array}$ & 2 & & $\begin{array}{l}\text { de } 15 \text { de janeiro a } 24 \text { de outubro. (art. } 120 \$ 2^{\circ} \text { do } \\
\text { dec. cit.) }\end{array}$ \\
\hline Paraíba & $\begin{array}{l}\text { Comunicado da Diretoria } \\
\text { Geral de Informações, } \\
\text { Estatísticas e Divulgação do } \\
\text { Ministério da Educação. } \\
\text { (23.6.933). Dec. n. } 1.042 \text { de } \\
\text { 13 de maio de 1938. } \\
\text { Programas de ensino (1938) }\end{array}$ & $\begin{array}{l}\text { 1- Grupo Escolar } \\
\text { 2- Escolas Reunida } \\
\text { 3- Escola Isolada (urbana) } \\
\text { 4- Escola Granja } \\
\text { 5- Escola Rural Modelo }\end{array}$ & 5 & 9 & $\begin{array}{l}\text { Escola Granja é aquela que, além do ensino de } \\
\text { letras do programa oficial, ministra praticamente } \\
\text { em terreno doado pela Prefeitura ou particular, } \\
\text { ensino de horticultura, jardinagem, silvicultura, } \\
\text { pomicultura, suinocultura, cunicultura, } \\
\text { sericicultura e culinária (art.8 do dec. cit.) } \\
\text { Escola Rural Modelo destina-se a ministrar o } \\
\text { ensino rural especial aos alunos dos bairros } \\
\text { pobres da cidade, que tenham sido aprovados nas } \\
\text { matérias do } 3^{\circ} \text { ano do curso primário e formar } \\
\text { um professorado de emergência (art. } 2^{\circ} \text { do dec. } \\
\text { cit.). } \\
\text { O ano letivo começa em } 16.2 \text { e termina em } 19.11 \\
\text { (com. cit.). }\end{array}$ \\
\hline Paraná & $\begin{array}{l}\text { Comunicado da Diretoria } \\
\text { Geral de Informações, } \\
\text { Estatística e Divulgação do } \\
\text { Ministério da Educação } \\
\text { (8.12.933) - Código de } \\
\text { Ensino de } 1917 \text { e decreto n. } \\
1.874 \text { de } 29 \text { de julho de } \\
1932^{2} \text {. }\end{array}$ & $\begin{array}{l}\text { 1- Grupo Escolar } \\
\text { 2- Escola Reunida ou } \\
\text { Agrupadas } \\
\text { 3- Escola Simples } \\
\text { 4- Escola Ambulante }\end{array}$ & 4 & $91 / 2$ & $\begin{array}{l}\text { As Escolas Ambulantes para os bairros onde o } \\
\text { Governo não houvesse estabelecido escolas ou as } \\
\text { não pudesse manter por ser insignificante a } \\
\text { população escolar. (Com. cit.). }\end{array}$ \\
\hline Pernambuco & $\begin{array}{l}\text { Comunicado da Diretoria } \\
\text { Geral de Informações, } \\
\text { Estatística e Divulgação do } \\
\text { Ministério da Educação } \\
\text { (8.6.933) - Ato n. } 1.239 \text { de } 27 \\
\text { de dezembro de } 1928 .\end{array}$ & $\begin{array}{l}\text { 1- Grupo Escolar } \\
\text { 2- Escola Isolada }\end{array}$ & 5 & 10 & $\begin{array}{l}\text { Á medida que forem construídos novos grupos } \\
\text { escolares devem ser suprimidas as Escolas } \\
\text { Isoladas (plano de reforma de 1928). }\end{array}$ \\
\hline
\end{tabular}




\begin{tabular}{|c|c|c|c|c|c|}
\hline Piauí & $\begin{array}{l}\text { Dec. n. } 1.438 \text { de } 31 \text { de janeiro } \\
\text { de } 1933-\text { Regulamento } \\
\text { Geral do Ensino }\end{array}$ & $\begin{array}{l}\text { 1- Grupo Escolar } \\
\text { 2- Escolas Agrupada } \\
\text { 3- Escola Singular } \\
\text { 4- Escola Nuclear }\end{array}$ & $\begin{array}{l}4 \\
3 \\
3 \\
1\end{array}$ & 9 & $\begin{array}{l}\text { Escolas Nucleares para rápida alfabetização em } \\
\text { povoados de população escassa. (art. } 96 \int 1^{\circ} \text { do } \\
\text { dec. cit.). } \\
\text { O ano letivo começa a } 15.2 \text { e termina } 25.11 \text {. Nas } \\
\text { Escolas Nucleares começa a } 1.3 \text { e termina } 25.11 \\
\text { (art. } 158 \text { e } \int \text { único). }\end{array}$ \\
\hline $\begin{array}{l}\text { Rio de } \\
\text { Janeiro }\end{array}$ & $\begin{array}{l}\text { Dec. n. 196- A de } 24 \text { de } \\
\text { dezembro de } 1936- \\
\text { Regulamento da Instrução } \\
\text { Pública Primária. }\end{array}$ & $\begin{array}{l}\text { 1- Grupo Escolar } \\
\text { 2- Escola Isolada (urbana) } \\
\text { (rural) } \\
\text { 3- Escola Típica Rural }\end{array}$ & $\begin{array}{l}5 \\
3 \\
3 \\
4\end{array}$ & $91 / 2$ & $\begin{array}{l}\text { Escola Típicas Rurais são escolas de educação } \\
\text { elementar e de iniciação profissional agrícola. (art. } \\
176 \text { do reg. cit.). }\end{array}$ \\
\hline $\begin{array}{l}\text { Rio Grande } \\
\text { do Norte }\end{array}$ & $\begin{array}{l}\text { Lei n. } 405 \text { de } 29 \text { de } \\
\text { novembro de } 1916 \quad- \\
\text { Regimento interno das } \\
\text { Escolas Isoladas }(1925) \\
\text { Regimento das Escolas } \\
\text { Rudimentares }(1925) .\end{array}$ & $\begin{array}{l}\text { 1- Grupo Escolar } \\
\text { 2- Escola Reunida } \\
\text { 3- Escola Isolada } \\
\text { 4- Escola Rudimentar (fixa) } \\
\text { (ambulante) }\end{array}$ & $\begin{array}{r}6 \\
4 \\
4 \\
2 \\
----\end{array}$ & 10 & $\begin{array}{l}\text { As Escolas Rudimentares poderão funcionar } \\
\text { como Escolas Ambulantes, por períodos ou } \\
\text { ciclos de } 5 \text { meses. (art. } 3^{\circ} \text { do reg. das escolas). O } \\
\text { ano letivo nos grupos escolares começa em } 1.2 \text { e } \\
\text { termina em } 30.11 \text {. (art. } 97 \text { - letra A da lei citada). } \\
\text { O ano letivo nas escolas isoladas e reunidas cai de } \\
1.2 \text { a 19.11. (art. 61). }\end{array}$ \\
\hline $\begin{array}{l}\text { Rio Grande } \\
\text { do Sul }\end{array}$ & $\begin{array}{l}\text { Comunicado da Diretoria } \\
\text { Geral de Informações, } \\
\text { Estatísticas e Divulgação do } \\
\text { Ministério da Educação } \\
(23.12 .933) \text { e Anuário } \\
\text { Estatístico do Brasil de } 1937 .\end{array}$ & $\begin{array}{l}\text { 1- Grupo Escolar } \\
\text { 2- Escolas Reunidas } \\
\text { 3- Colégio } \\
\text { 4- Escola Isolada }\end{array}$ & $\begin{array}{l}4 \\
3 \\
4 \\
3\end{array}$ & $81 / 2$ & $\begin{array}{l}\text { Os colégios têm a organização dos Grupos } \\
\text { escolares, mas são mais desenvolvidos, maior } \\
\text { matrícula, etc. (com. cit.). }\end{array}$ \\
\hline $\begin{array}{c}\text { Santa } \\
\text { Catarina }\end{array}$ & $\begin{array}{l}\text { Dec. n. } 794 \text { de } 2 \text { de maio de } \\
\text { 1914. Regulamento Geral da } \\
\text { Justiça Pública. Lei n. } 244 \text { de } \\
8 \text { de dezembro de } 1938 . \\
\text { Comunicado da Diretoria } \\
\text { Geral de Informações, } \\
\text { Estatística e Divulgação do } \\
\begin{array}{l}\text { Ministério da Educação } \\
(6.7 .933)\end{array}\end{array}$ & $\begin{array}{l}\text { 1- Grupo Escolar } \\
\text { 2- Escola Isolada }\end{array}$ & $\begin{array}{l}4 \\
3\end{array}$ & 10 & 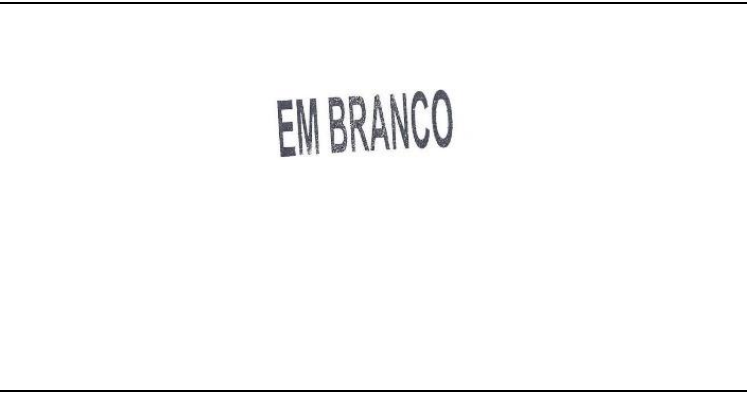 \\
\hline
\end{tabular}




\section{Dialogia}

\begin{tabular}{|c|c|c|c|c|c|}
\hline São Paulo & $\begin{array}{l}\text { Dec. n. } 5.884 \text { de } 21 \text { de abril } \\
\text { de } 1933 \quad \text { (Código de } \\
\text { Educação). Decretos n. } \\
\text { 6.047de } 19 \text { de agosto de } 1933 \\
\text { e } 7.268 \text { de } 2 \text { de julho de } 1935 .\end{array}$ & $\begin{array}{l}\text { 1- Grupo Escolar } \\
\text { 2- Grupo Escolar Rural } \\
\text { 3- Escola Isolada (urbana) } \\
\text { (rural) }\end{array}$ & $\begin{array}{c}5 \\
--- \\
3 \\
3\end{array}$ & 10 & $\begin{array}{l}\text { O } 5^{\circ} \text { ano do Grupo Escolar tem caráter pré- } \\
\text { vocacional. (art. } 1^{\circ} \text { do Código cit.). } \\
\text { O Grupo Escolar Rural ministra educação } \\
\text { primária e procura desenvolver pendor e aptidão } \\
\text { para atividades agrícolas e pastoris. (art. } 1^{\circ} \text { do dec. } \\
\text { cit.). }\end{array}$ \\
\hline Sergipe & $\begin{array}{l}\text { Dec. n. } 25 \text { de } 3 \text { de fevereiro } \\
\text { de } 1931 \text { - Regulamento do } \\
\text { Ensino Primário. }\end{array}$ & $\begin{array}{l}\text { 1- Grupo Escolar } \\
\text { 2- Escola Reunida } \\
\text { 3- Escola Isolada }\end{array}$ & $\begin{array}{l}4 \\
4 \\
4\end{array}$ & 9 & $\begin{array}{l}\text { O ano letivo começa em } 10.2 \text { e termina em } 20.11 . \\
\text { (art. } 51 \text { do dec. cit.). }\end{array}$ \\
\hline $\begin{array}{l}\text { Território do } \\
\text { Acre }\end{array}$ & $\begin{array}{l}\text { Inquérito relativo à clausula } \\
\mathrm{X} \text { do Convênio Nacional de } \\
\text { Educação (14.2.39) }\end{array}$ & $\begin{array}{l}\text { 1- Grupo Escolar } \\
\text { 2- Escola Isolada (urbana) } \\
\text { (rural) } \\
\text { 3- Escola Ambulante }\end{array}$ & $\begin{array}{c}---- \\
2 \\
2 \\
----\end{array}$ & EMBRANCO & $\begin{array}{l}\text { As Escolas Ambulantes são destinadas a } \\
\text { alfabetização intensiva das crianças que vivem } \\
\text { nos seringais e não podem permanecer por mais } \\
\text { de um ano em cada seringal. }\end{array}$ \\
\hline
\end{tabular}

*As nomenclaturas das tipologias de escolas foram reorganizadas no modo singular, ainda algumas palavras foram reescritas de acordo com o novo Acordo Ortográfico da Língua Portuguesa para melhor compreensão do leitor.

${ }^{1}$ Data ilegível.

${ }^{2}$ Redação alterada para a data correta do decreto n. 1.874 de 29 de julho de 1932 , no documento original consta decreto n. 1.874 de 2 de junho de 1932. Fonte: MES/INEP, 1939. 